\title{
Short-Term Influence of Fire on Herbaceous Composition, Diversity and Grass Biomass Production in Semi-Arid Savanna Woodland in Windhoek, Namibia
}

\author{
E Nepolo*, I Mapaure \\ Department of Biological Sciences, University of Namibia, Windhoek, P. Bag 13301, Namibia
}

\begin{abstract}
A comparative study on short term in fluence of fire on herbaceous composition and grass biomass production was conducted in a semi-arid savanna woodland in Windhoek, to assess differences in herbaceous composition and grass biomass production after a late dry season fire. The study revealed that herbaceous composition and grass cover differ significantly between the burned and unburned areas. Grass cover differed significantly $(p<0.001)$ between the burned and unburned areas. Fire removes aging grass materials, growth inhibitors and moribund hence, enhancing the vitality grasses. There were no significant differences in species richness $(t=-1.402, p>0.05)$, species diversity $(t=-1.391, d f=28, p>0.05)$, grass biomass production $(t=1.724, p>0.05)$ and forb densities $(t=0.361, p>0.05)$ between the burned and unburned areas..The study findings suggested that short term fire does have a significant impact on grass cover and herbaceous dominance and insignificant impact on grass biomass production, forb densities, species richness and diversity in short term, but fire impact on these plant attributes also depend on the intensity of fire and time frame.
\end{abstract}

Keywords Herbaceous Composition, Fire, Grass Biomass Production, Diversity, Semi-arid Savanna

\section{Introduction}

Fire is well known and described as a natural phenomenon and important component for maintaining savanna systems. When fire is described as a natural phenomenon, it becomes part of the ecology of savannas and plant species occurring in fire prone environments such the savannas are therefore highly adapted to fire occurrences.

For hundreds of thousands of years fire has played an essential role in determining the savannas in a complex and dynamic interaction with climate, soil, and herbivory[1]. Reference[2] stressed the importance of fire in savanna ecosystems as ecological factor that determined the plant species composition and vegetation structure through its occurrences. According to[2], savanna fires are usually occurring every $1-5$ years in wet savannas, therefore fire is more intense in wet savannas than in dry savannas, where lower water availability leads to low grass fuel load and production. Since plant species cannot escape fire in space, plant species that are not being able to resist the fire or to recover or re-grow quickly after the fire are usually rare in the savannas[3], as they are out competed by more fire tolerant species[2].

* Corresponding author:

enepolo@gmail.com (E Nepolo)

Published online at http://journal.sapub.org/ije

Copyright (C) 2012 Scientific \& Academic Publishing. All Rights Reserved
Whether lightning or man caused this unforeseen fire in both arid and semi-arid savannas, it does not only have a short term influence on the functioning of these ecosystems [4], but may also have residual effects on the following growing seasons, depending on successive climatic conditions. In an infrequent burn, fire usually removes the litter layer on the soil surface, removes moribund material and alters the microclimates and nutrients level in the surface soil[5]. Fire releases the light limitations created by litter, thereby allowing high-light species to more effectively competition[6]. It also allows soil temperature to increase, resulting in enhanced nitrogen mineralization from organic matter[7]. Then if there has been a large litter build up due to fire suppression, the above mentioned scenarios will cause a pulse of nitrogen availability, which can allow invasive species to establish, resulting in changes in species composition[8]. According to[8], the effects of fire on the structure and functioning of herbaceous layer of savannas retards the establishments and growth of woody shrubs in such systems, enhances grasses vitality through the removal of ageing plant part and any possible inhibitors that plants may contain[9].It also increases the nutritive values of plants[10] and results in the replacement of unpalatable species by more palatable ones[11].

Fire also acts as a natural selection force in the development of savanna species by synchronizing flowering and seed germination[12].In this study we assess the influence of fire on grass biomass production, herbaceous 
composition, and species diversity dynamics in semi -arid savanna woodland.

\section{Materials and Methods}

\subsection{Study Site}

This study was done in an Acacia woodland, located between UNAM and Western By-pass in Windhoek. The area is dominated and characterized by Acacia species mainly by, Acacia mellifera and Acacia erioloba. The herbaceous layer is dominated by grass species like Cenchrusciliaris, Eragrostisechinochloides, Stipagrostiscili ata, and $S$. uniplumis. The area has a climate that is characterized by summer rainfall that ranges between $200-$ $450 \mathrm{~mm}$, which greatly influences vegetation (life form) because it falls over a long time from October to April. The soil is predominantly, rocky, sand black and red clays, it has a coarse texture therefore it is classified as lithic leptosols [13]. The soil is the shallowest soils in Namibia and has very low water holding capacity and vegetation in this area is often subjected to drought. According to[14], the geology of the study area belongs to the Damara sequences made up of Khomas and Hakos groups. It cons is ts of metamorphic rocks, like mica, schist, calcareous schist, micaceous quartzite, impure marble and sandstones Treatment and control areas were selected at the site. The treatment was an area that was burned in November 2005, and the control was the adjacent unburned area. The study was conducted from the beginning of February to April 2006.

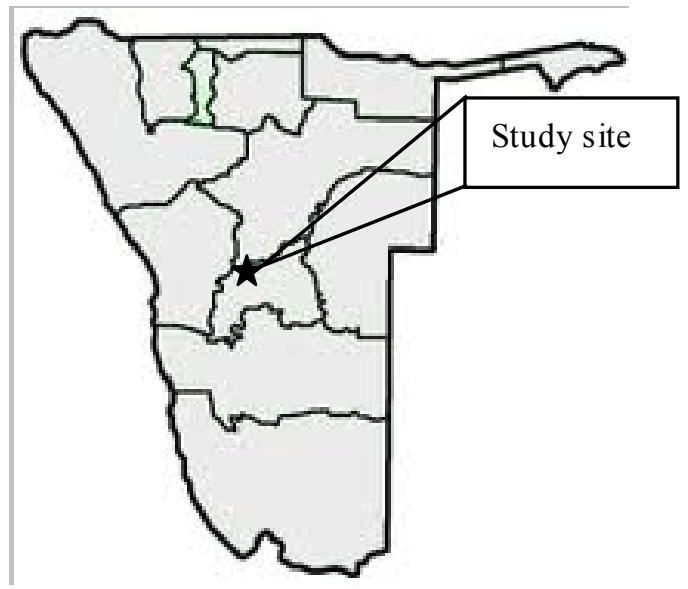

Figure 1. Map of Namibia showing the study site

\subsection{De marcation of Plots}

Within the study site using a tape measure, three $50 \mathrm{~m}$ line transects were laid out in each area (burned and unburned) in a defined compass direction from west to east at $30 \mathrm{~m}$ intervals. Along each line transect five plots measuring $5 \mathrm{~m} \mathrm{x}$ $5 \mathrm{~m}$ were de marcated systematically at $5 \mathrm{~m}$ interval along one side of the line transect in each area. For grass biomass measurements, within each $5 \mathrm{~m} \times 5 \mathrm{~m}$ two-clip sub plots measuring $1 \mathrm{~m} \times 1 \mathrm{~m}$ were demarcated in each plot at fixed location, one plot in southwest corner and the other plot in northeast corner.

\subsection{Me as urement and Ass ess ment of Plant Attributes}

In each sub plot grasses and forbs were looked for, identified to species level, and recorded. Specimens that were not identified in the field were collected and identified later at the UNAM herbarium. For forbs, the number of individuals were counted and recorded. All species with special features that were important for identification were described. Features involved in the description were growth form (whether, creeping, tufted or single stemmed) life form was recorded distinguishing phanerophytes, chameophytes, geophytes and hemicrophytes. Succulence was also noted as well as the hairiness of species. Overall, grass cover was visually estimated for each $5 \mathrm{~m} \times 5 \mathrm{~m}$ plot. Using a pair of secateurs all the grasses inside a $1 \mathrm{~m}$ x $1 \mathrm{~m}$ plot were harvested at about $1 \mathrm{~m}$ above the ground for grass biomass production. Grass biomass production was assessed at peak time where grasses were shedding flowers and maturing. Collected samples were placed in paper bags labelled with allocated code and taken to the laboratory for drying. For forbs densities, all individual forbs in their designated plots $(5 \mathrm{~m} \times 5 \mathrm{~m})$ were counted and for species richness all individuals of herbaceous species in each $5 \mathrm{~m} \times 5 \mathrm{~m}$ plot were counted and identified to species level.

\subsection{Labor atory Analys es and Ass ess ments}

In the laboratory, grass samples were dried in an oven at a temperature of $100{ }^{\circ} \mathrm{C}$ to a constant mass. Samples were weighted to determine the dry mass of the grass using a balance scale for each clip p lot and data recorded. Mass was determined by weighing the paper bag containing grass sample first to determine the mass of the bag plus that of grass sample. Grass sample were then removed from the paper bag and the paper bag was weighed without grass sample. Therefore, dry mass of the grass sample was determined by subtracting paper bag mass from the total mass of a bag and samples. Since there were two sub clips plots in each $5 \mathrm{~m}$ x $5 \mathrm{~m}$ plot, dry mass of these two sub clip plots were summed up to give dry mass in gram per square metre.

\subsection{Data Analysis}

Shannon-Weiner diversity index was calculated for forbs species diversity in burned and unburned areas, using the formula: $\mathrm{H}^{\prime}=-\Sigma\left(\mathrm{p}_{\mathrm{i}}\right)\left(\ln \mathrm{p}_{\mathrm{i}}\right)$, where $\mathrm{p}_{\mathrm{i}}$ is the proportion of total sample belonging to $i^{\text {th }}$ species.Grass biomass production was determined by combining subplot biomass data per $5 \mathrm{~m}$ $\mathrm{x} 5 \mathrm{mplot}$ and expressed as grams of dry matter per square metre $\left(\mathrm{g} / \mathrm{m}^{2}\right)$. The Kolmogorov-Smirnov test was used to test for the normality of $\mathrm{H}^{\prime}$, grass biomass, species richness and ford densities values.

All variables were normally distributed hence unpaired ttest was used to test for differences among variables. Species richness was expressed as the total number of individual plant species found in the burned and unburned areas. Forb 
densities was determined by dividing the total number of individuals by the area of the plot and expressed as number of individual per hectare. A Hierarchical Cluster Analysis (HCA) was used to compare forb species composition between the burned and unburned areas. This HCA was performed using Euclidean distance, basing on the presence or absence of a species from plot. Kruskal Wallis test was used to test for differences in grass cover between the burned and unburned areas.

\section{Results}

\subsection{Herbaceous Vegetation}

A total number of 6599 individual forbs were assessed in all combined two sites. This translated into 2883 forbs assessed in the unburned area and 3716 forbs in the burned area. A total number of 97 forbs species were assessed. This breaks down into 51 herb species assessed in the unburned area and 46 species assessed in the burned area. A total number of $10 \mathrm{~g}$ rass species were assessed in the burned area and 10 in the unburned area.

\subsection{Plant S pecies Composition}

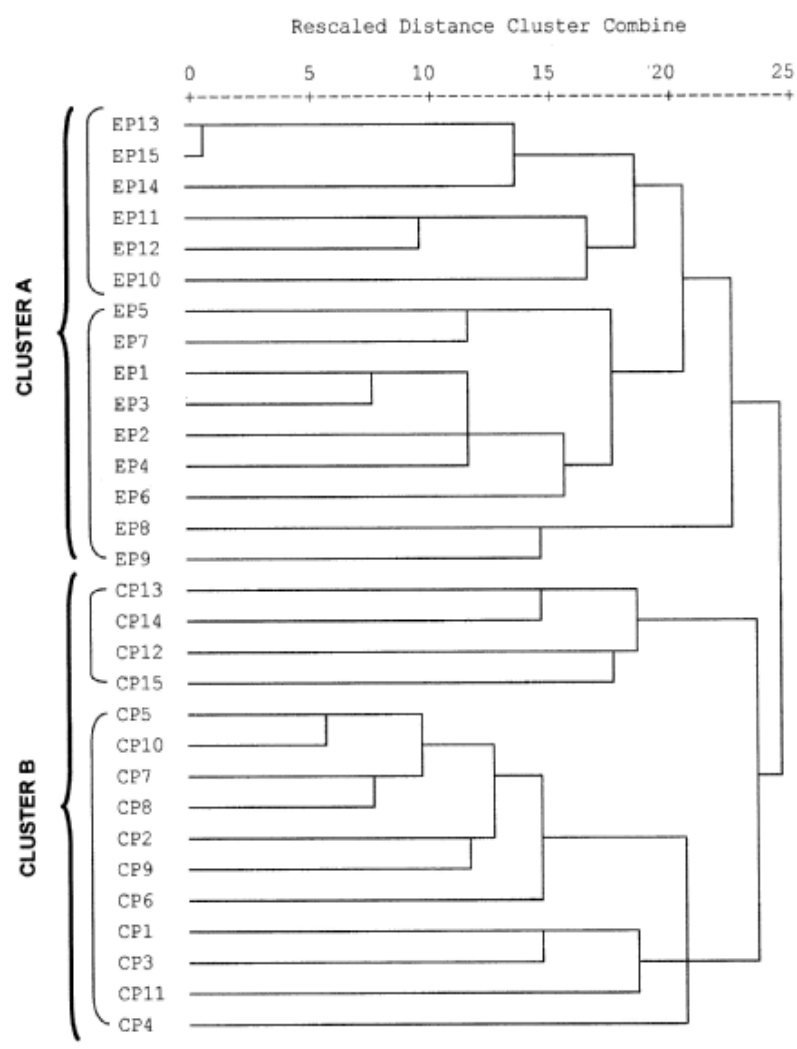

Figure 2. Differences in herbaceous composition in the burned area (EP) and unburned area (CP) in a semi - arid savanna woodland, Windhoek

Herbaceous species composition of the burned and unburned areas was significantly different. Hierarchical Cluster Analysis (HCA) clustered 15 experiment plots (EP) from burned area into one cluster and 15 control plots (CP) from unburned area into a separate cluster. In burned area
EP13 and EP15 were most similar in terms of species composition and such level of similarity was not observed in the unburned area (Figure 2). In the unburned area CP5 and CP10 were more similar in terms of species composition. CP4 has the lowest level of similarityin terms of species composition. In the burned area two separated sub clusters can be distinguished, sub cluster of EP13, EP15, EP14, EP11, EP12 and EP10 and a sub cluster of EP7, EP1 to EP9 according to their species composition.

The first sub cluster has common species such as Stipagrostisuniplumis, Eucastrumarabicum and Hibiscus calyphyllus. The second sub cluster has similar composition made up of Leucosphaerabainessii, Nesinalaticome and Cenchrusciliaris. Similar patterns were observed in the unburned (cluster B) area where species composition split into two sub clusters with similar composition. The first sub cluster CP13, CP14, CP12 and CP15 have a similar species composition in comparisonto other sub clusters, with common species such as Cenchrusciliaris, Eragrostistricho phora and Melhaniadamarana, while second sub cluster species composition has common species such as Enneapogoncenchroides, Leucosphaerabainessii and Ptychlobiumbiflorum.

\subsection{Species Richness}

Species richness of herbs ranged from 7 to 25 per plot in the burned area and from 15 to 29 species in the unburned area. There were large variations in species richness between the burned and an unburned site (Figure 3). However, the statistics analysis performed $(t=-1.402, p>0.05)$ revealed that there were no significant differences in herbaceous species richness between the burned and unburned area

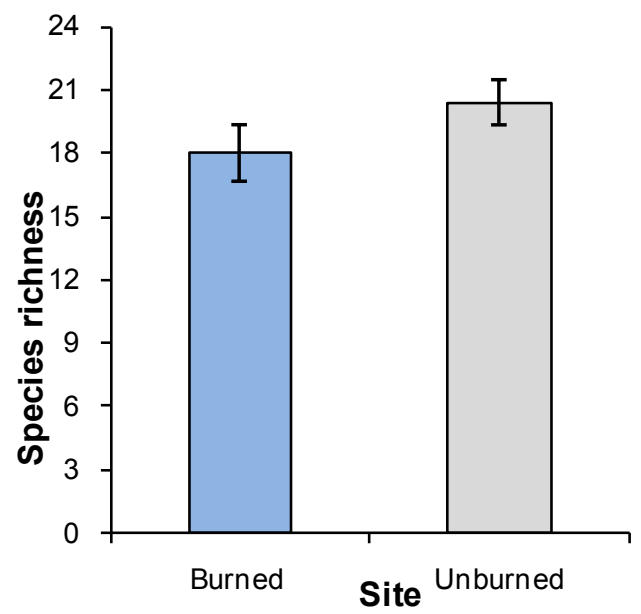

Figure 3. Mean differences in species richness of herbs between the burned and unburned sites, in a semi-arid savanna woodland, Windhoek

\subsection{For bs $S$ pecies Diversity}

Species diversity of forbs ranged from 0.77 to 2.69 in the unburned area and from 1.41 to 3.34 in the burned area (Figure 4). Even though, there was large variations in species diversity between the two sites, statistical comparisons $(\mathrm{t}=$ $-1.391, \mathrm{df}=28, \mathrm{p}>0.05)$, of the species diversity of forbs 
between the two sites indicated that there were no significant differences between the mean species diversity of forbs in the burned and unburned.

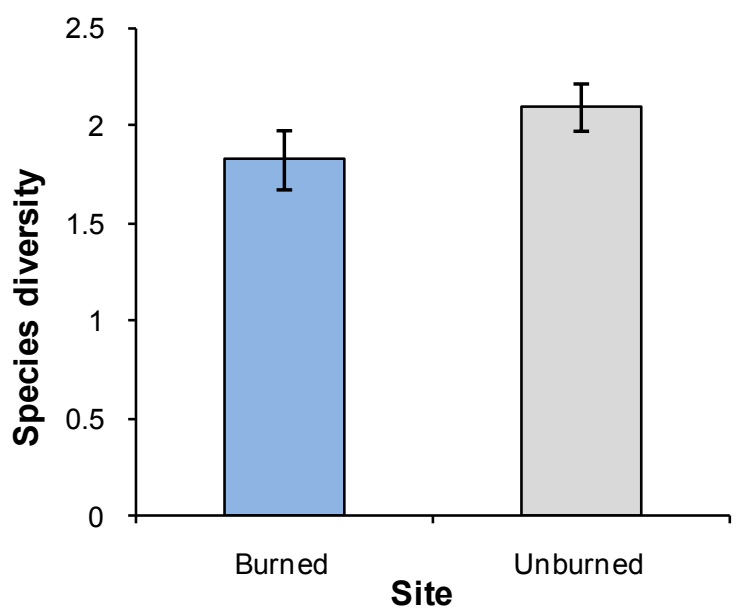

Figure 4. Mean differences in species diversity of forbs between the burned and unburned sites, in a semi-arid savanna woodland, Windhoek

\subsection{Overall Grass Cover}

The grass cover in the burned area ranged from 75 to $95 \%$ and from 60 to $90 \%$ in the unburned area (Figure 5). There were s mall variations in grass cover between the two sites. Statistical comparisons $(H=15.383, p<0.001)$ of overall grass cover between the sites indicated a significant differences in grass cover between the two sites. The burned site had significantly higher grass cover than the unburned site.

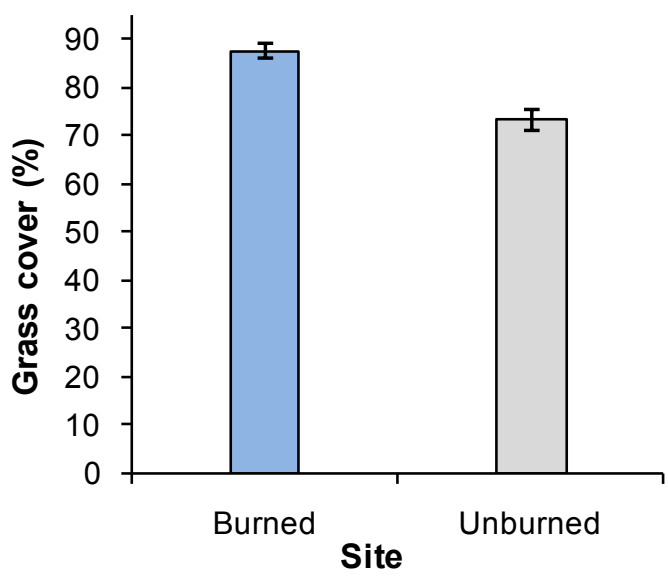

Figure 5. Mean differences in overall grass cover andtheir standard errors between the burned and the unburned site in a semi-arid savanna woodland, W indhoek

\subsection{Grass Biomass}

The grass biomass ranged fro $\mathrm{m} 63.65$ to $567.46 \mathrm{~g} / \mathrm{m}^{2}$ in the burned area, and fro $\mathrm{m} 29.18$ to $469.35 \mathrm{~g} / \mathrm{m}^{2}$ in the unburned area (Figure 6). There were wide variations in grass biomass among sites, resulting in large standard errors in the data sets. Statistical comparison $(t=1.724, p>0.05)$ between mean grass biomass between the sites revealed that there were no significant differences in grass biomass production between the two sites.

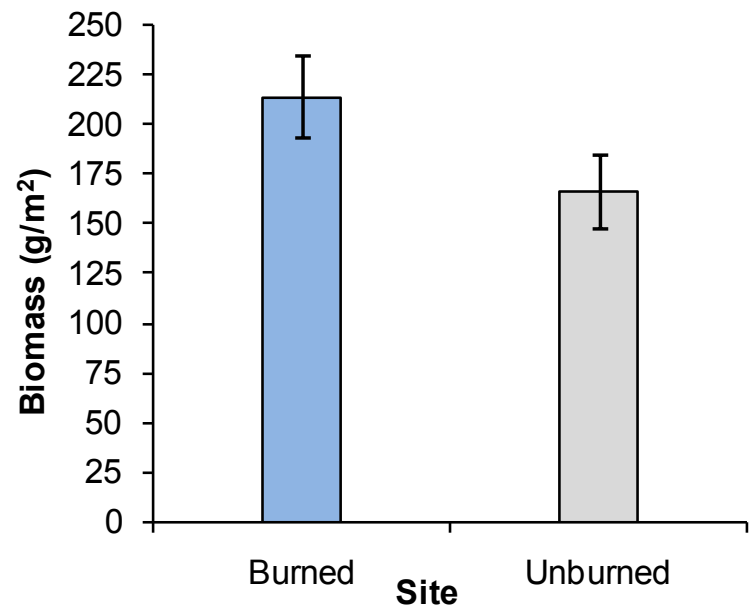

Figure 6. Mean differences in grass biomass production and their standard errors between burned and unburned sites in a semi-arid savanna woodland, Windhoek

\subsection{Forb Densities}

The density of forbs ranged from 5200 to $388400 /$ ha in the burned area and from in 17600 to 646800 /ha in the unburned area (Figure 7). There were wide variations in forb densities, resulting in large standard errors in the data sets. However, the statistics analysis $(t=0.361, \mathrm{p}>0.05)$ revealed that there was no significant differences in individual forb densities between the two sites.

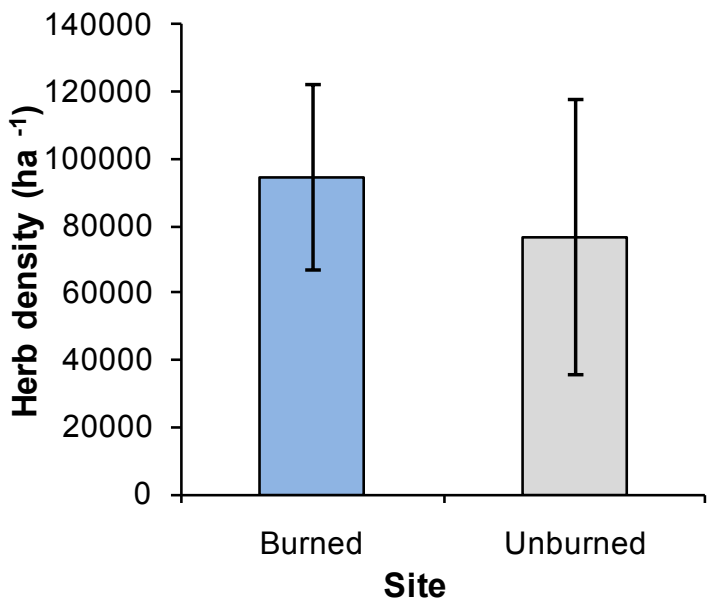

Figure 7. Mean differences in the densities of individual herbs between the burned and unburned sites in a semi-arid savanna woodland, Windhoek

\subsection{Frequency of Occurrence of Selected For bs}

Forbs that were dominant in the burned area were Hib iscus calyphyllus, Eucastruma rabicum, Co mmelinaafric ana and Nesinelaticome. Melhaniada marana, Leucosphaera bainessii , Ptychlobiumbiflorum, Pupalialappacea and Monechmadivaricatu m were do minant in the unburned area. Leucosphaerabainessii was the only species that was dominant in all sites (Figure 8). 


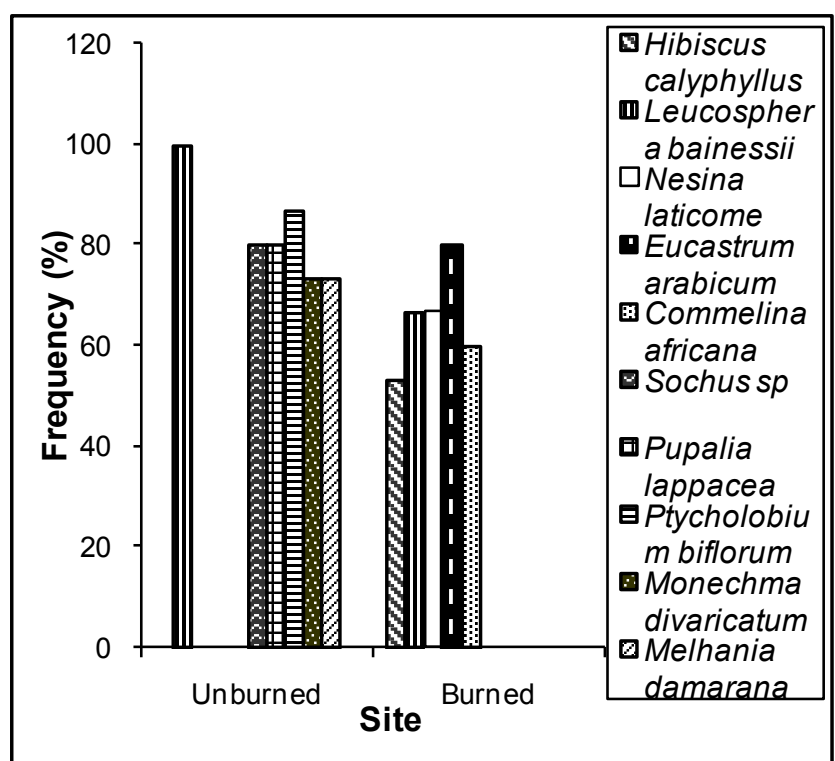

Figure 8. Frequency of occurrence of selected forbs species in the burned and unburned areas in a semi-arid savanna woodland, Windhoek

\section{Discussion}

Findings have stressed the importance of fire in savanna ecosystems as ecological factor that determined the plant species composition and vegetation structure through its occurrences. Savannas fire can be considered as relatively mild compared to forest fires[15], because they burn the herbaceous layer and young trees included in it, leav ing adult trees alive, affecting only tree recruitment and not adult survival.In the present study, herbaceous composition was found to differ significantly between the burned and the unburned area. Reference [16], stated that fire is known to suppress the growth of some plants and stimulate the growth of others, resulting in the replacement of former species in burned area by opportunistic ones. This replacement of former species will result in changes in plant composition. This was evident in the current study, where for instance, grass species such as Chrolisvirgata was found in the burned area and Fingerhuthiaafricana was suppressed by fire in the burned area. Even though, fire is known of causing replacement or addition of species into a habitat which does result in changing the species richness, there was no significance differences in species richness $(t=-1.402, p>$ $0.05)$ and forb diversity $(t=-1.391, \mathrm{df}=28, \mathrm{p}>0.05)$ between the burned and an unburned area in the current study.

According to the intermediate disturbance hypotheses by[17], low disturbance has little or no influence on species diversity, while intermediate disturbance results in higher species diversity and more diverse habitats. This could also be ascribed to the findings of this study, as the fire that did occurred could had minimal disturbance on the habitat, resulting in no changes in both species richness and forb diversity. The overall grass cover differ significantly $(\mathrm{H}$ $=15.383, p<0.001$ ), between the burned and the unburned sites. Grass cover was noted to be higher in the burned area in comparison to an unburned area. Reference[3] stated that fire stimulates the establishment and vitality of grasses in burned area through the reduction of competition with woody species. Moribund and aging parts of grasses can inhibit their gro wth. If there has been large litter build up on the soil surface due to the absence of fire, fire occurrence removes moribund material and alters the microclimate and nutrient levels in the surface soil[12],[18]. Therefore, the removal of these growth inhibitors by fire in the burned area has resulted in higher grass cover observed for this site.Studies on the influence of fire on grass covers have been made by several authors. According to[19] grass leaves grow from intercalary meristems and from new tillers from protected buds. In the absence of fire, tillers may end up covered by litter and moribund materials that could lead to a slower growth, which will result in lower grass cover in an unburned area. Conversely, if litter and moribund are removed by fire new tillers are exposed and they tend to grow fast and result in higher grass cover. Moreover,[20],[17] reported that fire increases plants nutrients availability in the soil, and act as a natural selective force in the development of grass species by synchronizing flowering and seed germination. Therefore, the observed higher grass cover in the burned area in this study could be attributed to the above cited reasons by several authors. A statistical comparis on of grass biomass between the burned and the unburned areas showed that there were no significant differences $(t=1.724$, $p>0.05)$ in grass biomass between the two sites. Fire is considered as a "super herbivore" [21] due to the fact that it consumes all grasses during its occurrence which results in new biomass in burned area. However, this new grass biomass in burned area sometimes could be tender but prolific in comparison with grass biomass in the unburned area, which contains moribund and aging grass parts. Therefore, if grass biomass in burned area is tender it may yield biomass that does not differ significantly from that of the unburned area, resulting in little or no differences in grass bio mass between the two sites. Many studies have been done in Southern Africa and have emphasized the effects of fire on grass production in savanna woodland ecosystems [22]. Several studies on peak above ground biomass with regard to fire revealed that burning increases grass production in such ecosystem[23],[3],[24]. These studies revealed that biomass production increases against the productivity gradient, at least relative to the quantities of biomass on the unburned areas of the same habitat[1].

Findings from these studies have pointed out that burned areas have high values of bio mass production, probably due to a nutrient pulse experienced after fire that can lead to higher grass biomass production for a short time than in unburned[15]. Similar observation was made in the current study. The burned area had high values of grass biomass production which ranged between 63.65 to $567.46 \mathrm{~g} / \mathrm{m}^{2}$ in comparison to the unburned area with a grass biomass production of 29.18 to $469.35 \mathrm{~g} / \mathrm{m}^{2}$. Since fire may reduce woody plant cover[18] it is not clear whether such an 
increase in grass production is the direct effect of fire or the effects of reduction cover or increased availability of soil nutrients. There were no significant trends $(t=0.361, p>$ 0.05 ) in forb densities between the burned and unburned sites. Fire is known to synchronize forbs recruitments in burned areas and newly established forbs suffers fromovercrowding allowing species with most seedlings and good competitors to dominate the community[8]. Therefore insignificance difference between the forb densities in the burned and unburned areas observed in the study could be due to opportunistic species occupying niches vacated by those eliminated by fire[10]. Moreover, fire does inhibit the establishment of certain forbs and promoting growth of others, which has densities which resembles that of forbs in the unburned area. Fire can also stimulate and increase flowering and, thus, seed production among shrubs and herbaceous species [25]. The germination of seeds of many plants species is dependent on fire providing one or more physical (temperature, light) and/or chemical (s moke, nutrients and gases) cues[23]. This does influence the dominance of forbs which germinated in the burned area after fire outbreak. In this study forbs such as Commelinaafricana, Nesinalaticome and Hibiscuscalyphyll us were more do minant in the burned area. Their do minance in the burned area could be as a result of fire enhancing the germination of these forbs through some modification to the environment that favour the germination of these forbs. According to[6] these modifications could be in the form of ash from burned litter which could increase soils nutritive value. So me seeds of plants are known to be fire dependent and they need to be exposed to fire to break their dormancy[21] so that they can grow after fire. Th is is evident from this study as forb species that were dominant in burned area differs from forb species which were dominant in the unburned area. Furthermore, fire does also kill seeds of some plants and only seeds of some species can withstand fire and germinates during the growing season. Dominance of species such as Pupalialappacea; Melhaniadamarana and Monechmadivaricatum in the unburned area could be ascribed to their capability to compete with other species for water and space. After fire, plant species tend to compete for space, and species that are good competitors happen to out-compete weaker competitors. This results in species that are good competitors dominating a certain habitat.

Hence, only species that are good competitors could establish and dominate the unburned area since species which are weak competitors are being replaced or thinned out by more effective competitors. According to[12], forb such as Leucosphaerabainessii is a good competitor hence it was occurring so dominantly in the unburned area.

\section{Conclusions}

After a late dry season fire, the comparison between the burned and unburned area in a semi-arid savanna woodland showed no significant differences in grass biomass production, species richness, species diversity and forb densities. However, significant ranges were found in herbaceous composition and grass cover. Therefore, fire has a significant impact on herbaceous composition and grass cover in a short term. The assessment of the short -term influence of fire on herbaceous composition and grass biomass production could only give an insight into what happened immed iately after fire. Therefore, short term fire may not have a significant impact on plant attributes such as grass biomass production, forb densities, species richness and diversity in short term. Consequently, fire impact depends also on fire regimes such as the time of burn and fire intensity. The time when an area is burned and the time when the study was conducted could have little or no impacts on plant attributes assessed in the study due to a long time frame between burning and plant attributes assessment.Short -term fire seems to have an impact on species dominance. Only few species were dominant in both areas. Therefore long -term assessment of fire, for instance working with the fire regime of the area would probably provide more detailed results and better understanding of the ecological process determining the herbaceous composition and grass biomass production of semi-arid savanna ecosystems after a late dry season fire.

\section{REFERENCES}

[1] Bessie,W.C and Johnson,E.A. The relative importance of fuels and weather on fire behaviour in subalpine forests. Ecology, vol. 76, pp. 747-762, 1995.

[2] Bond, W.J and van Wilgen, B. Fire and Plants: Population and community biology series 14.Chapman and Hill Publisher, London, 1996.

[3] Booysen, P.de V and Tainton, N.M. (eds). Ecological Effects of Fire in Southern African Ecosystems, Ecological Studies 48, Springer - Verlag, Berlin, 1984.

[4] DeBano, L.F., Neary, D.G and Folliott, P.F. Fire's effects on Ecosystems. Wiley \& Sons Inc, New York, 1998.

[5] Frost, P.GH. The response of savanna organisms to fire.In.Ecology and management of the world's savannas, edsTothill, J.C \& Mott, J.J., Ann. Acad. Sci, pp. 232 -237, Canberra, 1985.

[6] Frost, P.G.H and Robertson, F. The ecological effects of fire in savannas. In: Walker, B.H. (ed). Determinants of Tropical Savannas.IRL Press Limited, Oxford, 1985.

[7] Gillon, D. Studies on herbaceous layer production in Burkeaafricana savanna. MSc thesis, University of Pretoria, 1983.

[8] Grossman, D., Grunow, J.O and Theron, G.K. The fire with and without subsequent defoliation, on the herbaceous layer of the Burkeaafricana savanna. ProcGrassld. Soc. vol. 16, pp. $117-120,1981$.

[9] Heinl, M., Silva, J and Tacheba, B. Vegetation changes after single fire events in the Okavango Delta wetland, Botswana. 
South African Journal of Botany, vol. 70, no 5, pp. 695 -704, 2004.

[10] Keeley, J.E and Carrington, M.E. Comparison of post -fire seedling establishment between scrub communities in Mediterranean and non-Mediterranean climate ecosystems. Journal of Ecology, vol. 87, pp.1025 -1036, 1999.

[11] Keeley, J.E and Fortheringham,C.J, C.J. Smoke -induced seed germination in California chaparral .Ecology, vol. 79, pp. $2320-2336,1998$.

[12] Lavorel, S., Mclntyre,S and Grigulis,K. Plant response to disturbance in Mediterranian grassland: How many functional groups? Journal of Vegetation Science, vol .10, pp. $661-672,1999$.

[13] Mendelsohn,J. Jaris,A. Roberts,C and Robertson,T. Atlas of Namibia: A portrait of the land and its people. David Philip Publishers,Cape Town, 2002.

[14] Namibia Ministry of Mine and Energy. Annual Report: Geological Survey of Namibia. Windhoek, 1999.

[15] Neary, D.G., Kloppatek, C.C., DeBano, L.F and Effoliot, P.F Fire effects on below ground sustainability: A review and synthesis. Forest Ecology and Management, vol. 122, pp. 247-260, 1999.

[16] Oguntala, A.B. The effects of fire on aspects of nitrogen cycling in Olokemeji Forest Reserve, Nigeria.In.Nitrogen cycling in Western African Ecosystem.ed.T.Rosswall, pp.317 -323. Swedish Academy of Sciences Stockholm, 1980.

[17] O'Connor, T.G. A synthesis of field experiments concerning the grass layer in the savanna regions of southern Africa.S.ANat.Sci.Prog.Rep, vol. 114, pp. 1-126, 1985.
[18] Rutherford, M.C. Annual plant production-precipitation relationships in arid and semi - arid regions. S. Afr.J.Sci. vol. 76, pp. 53-56, 1980.

[19] San Jose, J.J., \& Medina, E. Effect of fire on organic matter production and water balance in a tropical savanna.In: Golley,F.B\&Medina,E. (eds).Tropical Ecological systems. Springer-Verlag,Berlin, 1975.

[20] Synman,H.A. Fire and the dynamics of semi-arid grassland: influence of plant survival reproductively and water use efficiency: African Journal of Range and Forage Science. Vol. 20, pp. $29-30,2003$.

[21] Synman, H.A. Short-term response in reproductive following an unplanned fire in a semi-arid rangeland of South Africa. Journal of Arid Environment, vol. 56, pp. 465 -485, 2004.

[22] Trapnell, C.G. Ecological results of woodland burning experiments in Northern Rhodesia. J. Ecol vol.47, pp.129 $-168,1959$.

[23] Vogl, R.J. Effects of fire on grasslands, In: Fire and Ecosystems, Kozlowski, T.T. \&Ahgren, C.E. (eds), pp.139-194, Academic Press, New York, 1974.

[24] Van Wilgen, B.W and Forsyth, G.G. Regen eration strategies in Fynbos plants and their influence on stability of community boundaries after fire, in Fire in South African Mountain Fynbos, (eds) B.W van Wilgen, D.M. Richardson, F.J. Kruger and H.J. van Hensbergen), Ecological Studies 93, Springer -Verlag, Berlin, pp. 81 -107, 1992.

[25] Trollope, W.S.W. Fire in Savanna. In: Booysen, P. deV, Tainton, M.N. (eds), Ecological Effects of Fire in Southern African Ecosystems, Ecological Studies 48,Springer -Verlag, Berlin, 1984. 